\title{
Lights, camera, action: Microbiology laboratory teaching in the spotlight
}

\author{
Katrina Lacey ${ }^{1}$, J. Gerard Wall ${ }^{1,2}$ \\ ${ }^{1}$ Microbiology, National University of Ireland, Galway (NUI Galway), Galway, Ireland, \\ ${ }^{2}$ Centre for Research in Medical Devices (CÚRAM), NUI Galway, Ireland.
}

\begin{abstract}
Broadening of access to higher education, leading to increasing class sizes, presents particular challenges in teaching specialised, laboratory-based subjects such as Microbiology. The Republic of Ireland has seen a $20 \%$ increase in undergraduate student numbers in the past ten years, with this trend set to continue in the near future. To complement traditional learning approaches, we have designed, produced and trialled a comprehensive suite of teaching videos that demonstrate common techniques taught in our Microbiology degree programme. The 42 videos, each of 4-9 minutes duration, were filmed in-house using a professional film maker. Videos were designed for viewing before linked laboratory sessions to increase student engagement, assist learners with little prior technical experience to process core concepts, and improve the quality of hands-on practical training in the laboratory. Student reaction to a pilot release was exceptionally positive, underlining the videos' effectiveness for visual learners and the added value of the content due to its bespoke nature. The complete video collection will be amalgamated into our B.Sc. programme in 2019-20. The initiative is expected to enhance students' experience in hands-on laboratory sessions, promote active learning by blending video into traditional teaching programmes, and support reflective study through their availability.
\end{abstract}

Keywords: visual learning; instructional videos; microbiology; laboratory; blended learning. 


\section{Introduction}

Technology and the digital world have brought about radical and rapid change in the way knowledge is accessed and disseminated. According to Siemens (2005), learning is no longer an individual or solo activity but has been replaced by something that is performed collectively. Traditional methods of teaching have been eclipsed by the alternative of flipped learning. Once viewed as a means of allowing learners to engage with lecture material (Lage et al., 2000), this has now transformed into a pedagogical approach in which students are provided with material prior to their class to enabling a more active learning environment to develop during timetabled class time. In addition, it provides an opportunity for students to deepen their understanding of course materials through active learning exercises, assigned activities, laboratory sessions and other practical applications. In this approach, students present for class pre-prepared for the relevant material through watching instructional videos or researching materials assigned by the teacher. In resource-intensive laboratory environments in particular, the primary focus can now shift to helping students with individual difficulties and to more complex techniques (Bergmann and Sams, 2012). This flipped classroom approach blends face to face learning during contact hours with distance learning outside of class (Halili and Zainuddin, 2015). Coupled with blended learning, this flipped classroom structure creates a student-centred approach to learning in which the instructor serves as facilitator and motivator whereas the student comes to the fore and is more active in the classroom (Bergmann and Sams, 2012). This allows students to better dictate their own pace of learning, and to be more effective and focused in the classroom (Fulton, 2012).

\subsection{Background and Motivation for the Work}

The Discipline of Microbiology at the National University of Ireland, Galway has amassed over 50 years of teaching and research excellence in the fields of infectious diseases, environmental microbiology and marine microbiology. Teaching programmes include a fouryear B.Sc. programme in Microbiology, as well as postgraduate Diploma, Masters and Ph.D. programmes. The B.Sc. is a very popular choice with undergraduate students, resulting in large student cohorts from $1^{\text {st }}$ year (approximately 620 students), through $2^{\text {nd }}(210)$ and $3^{\text {rd }}$ (150) years, to final year (60). With this in mind, we identified the potential benefits to our students of creating a repository of instructional videos to cover essential laboratory-based methods, to complement traditional teaching approaches. Online searches revealed a dearth of technical videos detailing fundamental techniques and threshold concepts over the breadth and specificity required. We therefore undertook to develop a suite of teaching videos, demonstrating microbiology techniques, that would be freely available online to second and third level institutions and other interested parties. The goal of this e-learning initiative was multi-faceted: to promote student engagement in our taught programmes; to increase the 
quality of our practical and theoretical training courses; to ease the progression to third level of students from non-technical backgrounds; and to enhance NUI Galway's, and the Discipline of Microbiology's, international profile in the biosciences field and in researchled teaching.

\section{Methodology}

\subsection{Project Design}

Academic and technical staff involved in delivery of the $2^{\text {nd }}$ and $3^{\text {rd }}$ year Microbiology programmes were canvassed to compile a list of techniques for inclusion in the project. Staff were tasked with identifying techniques with core threshold concepts that are difficult to demonstrate to a large student cohort and whose teaching would be expected to be improved by the availability of a dedicated video resource. Duplicate suggestions were eliminated and a short-list of techniques was circulated to academic and technical staff for feedback. More complex methods were divided into autonomous sections to keep videos to 4-9 mins in length where possible. Five equipment instruction videos, appropriate for Health and Safety-related training of final year undergraduate and postgraduate students, were also included in the list. The final list of 42 videos was used in a funding application and in procuring a film maker partner for the project.

\subsection{Preparation for Filming}

A filming location was selected during an initial site visit by the film maker. The selection prioritized using a laboratory environment familiar to target student groups in order to increase engagement with the final product, and aspects such as light quality and uninterrupted availability for ten weeks. Four PhD students, with collective expertise in the techniques to be filmed, were hired and each allocated the filming space for two weeks to prepare for and practice their respective techniques. All equipment and reagents were provided exactly as used in the target laboratory teaching sessions. In a final run, each technique was filmed, from a single viewpoint, using a fixed digital camera. These "homemade” videos (see Figure 1(a)) were supplied to the film production company to provide an overview of video content and timing guide prior to formal filming of the desired videos.

\subsection{Filming Process}

Filming took place on the NUI Galway campus over eight days in June 2018. Three cameras were used: overhead, elevated to the students' right, and over the students' left shoulder (see Figure 1(b)). Additional lighting was used when necessary. Extensive filming and re-takes were carried out over days one and two, after which videos were filmed at a rate of 
approximately six per day. Audio was recorded later in the university recording studio, with the help of personnel from the Centre for Learning and Teaching (CELT).

\subsection{Post-production}

Editing of three camera feeds and audio occurred over a six-month period from September 2018. Batches of four to eight video drafts were typically provided by the film maker for review. After incorporation of the authors' suggested edits, a meeting between film editor and authors to resolve remaining questions completed each two-week cycle. Each video required a minimum of three iterations of this process. Additional audio was recorded during the editing process for incorporation into a number of videos. The intro and outro were finalised through a similar process, with the former combining views of the NUI Galway campus with laboratory images, and the latter crediting contributors to the videos and the source of funding. Finally, a dedicated YouTube channel was created for widespread, free distribution of the final suite of videos.

\subsection{Pilot Release and Feedback}

During post-production, two batches of three videos each were shown to $2^{\text {nd }}$ year $(n=210)$ and $3^{\text {rd }}$ year $(n=41)$ Microbiology student cohorts, as part of teaching of the relevant techniques in scheduled laboratories. In the former group, video resources had not previously been used in formal teaching. For the latter group, students had previously been directed to available video resources online, which covered the same experimental techniques but with some technical differences from their laboratory practices. Both groups were surveyed using an anonymous questionnaire and data processed using Excel.

\section{Results}

\subsection{Video Production and Editing}

Funding was secured for the two-year project in May 2017 from NUI Galway's Student Project Fund, an internal competitive funding source with priorities such as the development of online teaching resources and supporting the transition of students to Higher Education. Slipjig Media (www.slipjigmedia.com) were contracted in November 2017 to film the videos and a project manager and four $\mathrm{PhD}$ students with appropriate expertise were selected in April 2018 after an open call for applications to Microbiology researchers. Initial videos were assembled by the film editor and reviewed by the authors and project manager. This process identified extensive edits to video content, editing and re-timing of audio, and insertion of labels and other highlights to pinpoint specific video content and emphasise core concepts. Reviewing and editing of drafts was staggered but all $1^{\text {st }}$ drafts were completed by December 2018, $2^{\text {nd }}$ drafts by January 2019 and final versions will be completed by February 2019. Pre- 
final versions of all videos will be viewed by three members of staff prior to proceeding to final production.

The suite of videos (Figure 1(c)-(f)) presents core theoretical concepts in the biosciences and spans a wide spectrum of methods, ranging from fundamental bacterial culturing methods, through the use of commercial microorganism identification tests, to more sophisticated techniques to analyse DNA and protein molecules. Instruction videos for the use of Health and Safety-related instrumentation have also been included.

(a)

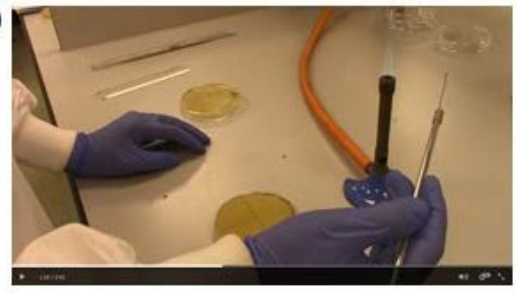

(c)

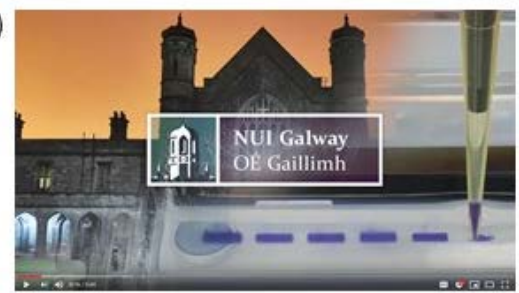

(e)

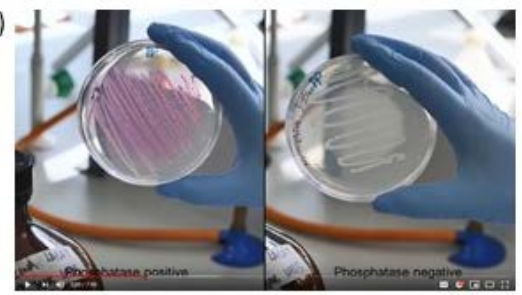

(b)

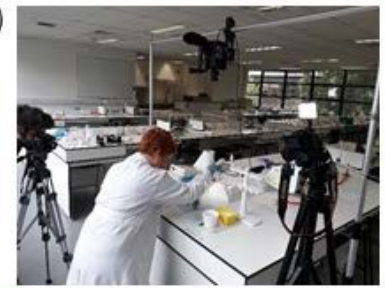

(d)

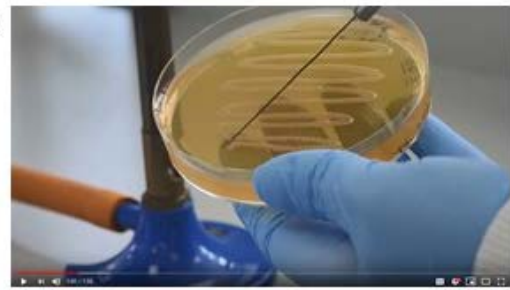

(f)

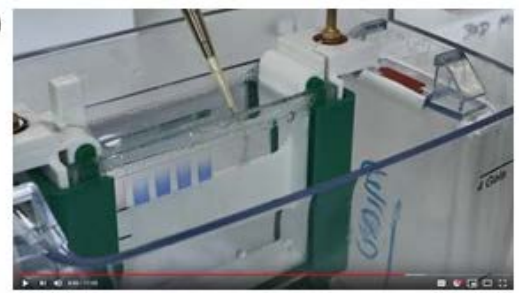

Figure 1. (a) Screen shot from in-house video. (b) Laboratory set-up with professional film company. (c) Sample screen shot from common introduction of videos. (d)-(f) Sample screen shots from videos demonstrating (d) bacterial culturing, (e) biochemical characterisation of microorganisms and (f) protein analysis techniques.

\subsection{Student Evaluation}

After viewing in the appropriate laboratory practical sessions, completed feedback forms on pre-final videos were returned by 155 ( $n=201 ; 73 \%) 2^{\text {nd }}$ year and 41 (100\%) $3^{\text {rd }}$ year Microbiology students. In the case of $2^{\text {nd }}$ year classes for whom video-based learning was new in their course, $94 \%$ of students responded that the video material helped them to engage better with the content of the laboratory session (Figure 2). A large majority of students indicated that the videos were very (87\%) or slightly (11\%) helpful to them in subsequently carrying out the techniques in the laboratory, while $84 \%$ expected they would watch the 
videos as preparatory material for laboratories and 95\% of respondents expected the videos to be helpful as study aids after completion of the hands-on training. Of the students who provided additional comments, the most frequent feedback ( $9 / 15$ comments) concerned the high value of the videos for visual learners and visual learning.

(a)

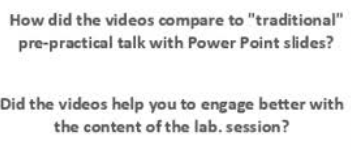

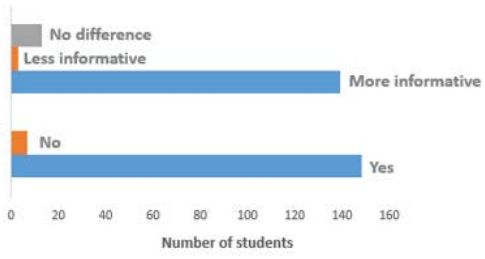

(b)

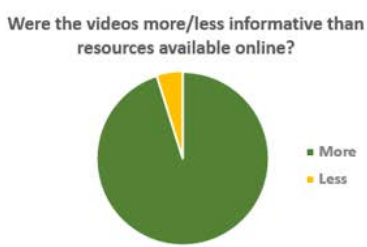

Figure 2. Sample results from pilot survey of (a) $2^{\text {nd }}$ year and (b) $3^{\text {rd }}$ year Microbiology students.

For the $3^{\text {rd }}$ year class who were accustomed to using videos in their learning, albeit not adapted to their equipment or procedures, 95\% found the "in-house" videos to be more informative for their learning than those available online. Again, large majorities of students indicated that they would watch the videos in preparation for lab sessions (100\%) or later as a revision/study aid (98\%). Of the $73 \%$ of students who supplied additional comments, the most recurrent theme (9/30 comments) was the value added to students' learning by using bespoke rather than generic resources, which respondents identified as sometimes poorly suited to the technical requirements or precise goals of the laboratory session.

\section{Discussion}

Cursory inspection of the research literature highlights that at third level, the ever increasing large class size poses particular problems for staff and students alike, often contributing to less effective teaching and learning (Mulryan-Kyne, 2010). While traditional lecturing still remains the predominant teaching approach used for large student groups, the incorporation of educational videos has now become an important part of the curriculum, providing an important content-delivery tool in many flipped, blended and online classes (Brame, 2016). In addition, several meta-analyses have shown that technology can actively enhance learning (Means et al., 2010; Schmid et al., 2014), and numerous other studies have shown that video, specifically, can be a highly effective educational tool (Allen and Smith, 2012; Kay, 2012; Stockwell et al., 2015).

At the outset of this project, our objective was to create online instructional videos, many demonstrating technically complex and miniature methods, which would be a valuable addition to our lecture-based teaching and traditional pre-practical talks. Preliminary feedback from the pilot evaluation indicates the video content produced was extensively 
welcomed by students and is likely to promote self-study practices and increase competencybased skills in the laboratory.

A large-scale, student-centred study of the effectiveness of the videos is planned after their inclusion in teaching throughout the 2019-20 B.Sc. academic programme. The pedagogic value of the video collection to final year undergraduate students and Ph.D. researchers who demonstrate $2^{\text {nd }}$ and $3^{\text {rd }}$ year laboratory courses to develop teaching and science communication skills will also be evaluated. Finally, a GoPro-based approach in which students record themselves while carrying out techniques in the videos, followed by submission for grading and recognition in the form of a digital badge, is envisaged.

\section{Acknowledgements}

The authors acknowledge the assistance of Ph.D. students Jasmine Connolly, Neyaz Khan, Grainne McAndrew and Maura Tilbury; Michael Coughlan for providing audio; and Aileen Gill for script writing and project management. The NUI Galway Student Project Fund is thanked for financial support.

\section{References}

Allen, W. A. \& Smith, A. R. (2012). Effects of video podcasting on psychomotor and cognitive performance, attitudes and study behaviour of student physical therapists. Innovations in Education and Teaching International, 49(4), 401-414. doi: 10.1080/14703297.2012.728876.

Bergmann, J. \& Sams, A. (2012). Flip your classroom: Talk to every student in every class every day. Washington, DC: International Society for Technology in Education.

Brame, C. J. (2016). Effective educational videos: Principles and guidelines for maximizing student learning from video content. CBE Life Science Education, 15, 1-6. doi: 10.1187/cbe.16-03-0125.

Fulton, K. (2012). Upside Down and Inside Out: Flip Your Classroom to Improve Student Learning. Learning \& Leading with Technology, 39(8), 12-17.

Halili, S. H. \& Zainuddin, Z. (2015) 'Flipping the classroom: What we know and what we don't.' Online Journal of Distance Education and e-Learning, 3(1), 28-35.

Kay, R. H. (2012). Exploring the use of video podcasts in education: a comprehensive review of the literature. Computers in Human Behavior, 28(3), 820-831. doi: 10.1016/j.chb.2012.01.011.

Lage, M., Platt, G., \& Treglia, M. (2000). Inverting the classroom: A gateway to creating an inclusive learning environment. Journal of Economic Education, 31(1), 30-43. doi: 10.1080/00220480009596759.

Means, B., Toyama, Y., Murphy, R., Bakia, M., \& Jones, K. (2010). Evaluation of EvidenceBased Practices in Online Learning: Meta-Analysis and Review of Online Learning Studies, Washington, DC: US Department of Education. 
Mulryan-Kyne, C. (2010). Teaching large classes at college and university level: challenges and opportunities. Teaching in Higher Education, 15(2), 175-185. doi: 10.1080/13562511003620001.

Schmid, R. F., Bernard, R. M., Borokhovski, E., Tamim, R. M., Abrami, P. C., Surkes, M. A., Wade, C. A., \& Woods, J. (2014). The effects of technology use in postsecondary education: a meta-analysis of classroom applications. Computers and Education 72, 271291. doi: 10.1016/j.compedu.2013.11.002.

Siemens, G. (2005). Connectivism: A learning theory for the digital age. International Journal of Instructional Technology and Distance Learning, 2(1), 3-10.

Stockwell, B. R, Stockwell, M. S., Cennamo, M., \& Jiang, E. (2015). Blended learning improves science education. Cell, 162(5), 933-936. doi: 10.1016/j.cell.2015.08.009. 